\title{
New Segmented Polyurethane Ureas Based on 4,4'-Dicyclohexylmethane Diisocyanate and on Various Soft Segments
}

\author{
NATHALIE SAMSON, FRANÇOISE MÉCHIN, JEAN-PIERRE PASCAULT \\ Laboratoire des Matériaux Macromoléculaires, UMR CNRS n5627, \\ Institut National des Sciences Appliquées de Lyon, \\ Bât. 403, 20, avenue Albert Einstein, 69621 Villeurbanne Cedex, France
}

\begin{abstract}
Linear segmented polyurethane ureas were prepared from 4,4'-dicyclohexylmethane diisocyanate ( $\left.\mathrm{H}_{12} \mathrm{MDI}\right), 4,4^{\prime}$-diamino-3,3'-dicyclohexyl methane (3DCM), and various hydrophilic and hydrophobic soft segments. Kinetic studies of the synthesis of the diisocyanate-terminated prepolymers revealed that the use of too little reactive polyols (that is, polyoxypropylene that bears secondary hydroxyls) could be rather tricky; the noncatalyzed reaction is very slow, but the use of a catalyst soon triggers the formation of side products, and the processing window consequently becomes quite short. Microcalorimetric and dynamic mechanical measurements showed that all the materials were highly phase-segregated elastomers and displayed good mechanical properties up to high temperature (typically $180^{\circ} \mathrm{C}$ ), provided that they had been postcured properly; in this respect, the dramatic effects of isolated (nonchemically linked) hard segments, as well as of too low postcuring temperatures, were demonstrated. Polyurethane ureas compare well with polyureas, and their synthesis can be a good way to cope with the lack of well-adapted commercial diamino-terminated prepolymers.
\end{abstract}

Key words: dicyclohexylmethane diisocyanate; segmented polyurethane ureas; postcuring; elastomers with good thermal stability; thermomechanical properties

Published in Journal of Applied Polymer Science vol. 70, 2331-2342, 1998

Correspondence to: F. Méchin. 


\section{INTRODUCTION}

Linear segmented polyurethanes consist of alternating soft segments (formed by the flexible dihydroxytelechelic prepolymer) connected by hard segments resulting from the polycondensation of diisocyanates with diol chain extenders. ${ }^{1}$ By adjusting the chemical nature and respective amounts of the reagents, it is thus possible to obtain a wide range of materials with tailored properties. Thermodynamic immiscibility between hard and soft segments often induces phase separation, which generates a two-phase morphology and confers an elastomeric character to these thermoplastic materials. Their engineering properties are determined, to a large extent, by phase separation.

In a recent article, ${ }^{2}$ we demonstrated how the use of urea linkages, instead of urethanes, could lead to materials with improved thermomechanical properties. However, such polymers must be prepared from diaminotelechelic flexible prepolymers, among which only a limited number are commercially available, most of them being polyether chains. In contrast, a wide range of polyols can be found, hydrophilic or hydrophobic, and sometimes with an excellent thermostability. Their lower reactivity can also facilitate material processing. In this respect, the present work presents the elaboration and characterization of new polyurethane ureas with structures similar to the previously studied polyureas ${ }^{2}$ and gives a comparison between urethane and urea linkages. The influence of the chemical nature of the soft segment on the static and dynamic mechanical properties is also described.

\section{EXPERIMENTAL}

\section{Materials}

All reactant structures are shown in Table I. Desmodur W (Bayer) is a mixture of the 3 isomers (trans, trans, cis,trans, and cis,cis) of 4,4'-diisocyanatodicyclohexylmethane $\left(\mathrm{H}_{12} \mathrm{MDI}\right)$ and was used without purification. It is a low-viscosity liquid with an isocyanate equivalent mass of $131 \mathrm{~g} \cdot \mathrm{mol}^{-1}$ (determined by isocyanate titration using the ASTM D1638-74 method).

PTMO2000 (Aldrich) is an $\alpha, \omega$-dihydroxy-terminated poly(oxy-tetramethylene) with a molar mass of $2000 \mathrm{~g} \cdot \mathrm{mol}^{-1}$ and a hydroxyl functionality of 2.0 .

PPO2000 (Aldrich) is an $\alpha, \omega$-dihydroxy-terminated poly(oxy-propylene) with a molar mass of about $2100 \mathrm{~g}^{\mathrm{mol}}{ }^{-1}$. The main advantage of this reactive oligomer is its very low polydispersity index. However, because of the presence of some monofunctional species resulting from the synthesis, ${ }^{3}$ its hydroxyl functionality is also lower than 2.0. The analysis of its microstructure by ${ }^{1} \mathrm{H}$ and ${ }^{13} \mathrm{C}$ nuclear magnetic resonance $(\mathrm{NMR})^{4}$ revealed that the inversion rate was very low (only 1.3 to $2.5 \%$ primary hydroxyl groups), whereas 0.22 nonreactive extremities (allyl or methyl vinyl) could be found for every 100 propylene oxide units, that is, a number average functionality of 1.92 .

EPOL (Atochem Idemitsu) is a hydroxy-terminated hydrogenated polyisoprene ${ }^{5}$ with a molar mass of about $2500 \mathrm{~g} \cdot \mathrm{mol}^{-1}$ and an average functionality between 2.3 and 2.4 (OH equivalent weight: 1087 g. $\left.\mathrm{mol}^{-1}\right)$.

Priplast 3197 (C36*, Unichema International) derives from oleic acid dimers. According to the Unichema notice, it results from the condensation of 2 dihydroxy-terminated dimer molecules (Pripol 2033) with 1 dicarboxy-terminated dimer molecule (Pripol 1009), as follows ${ }^{6}$ : 


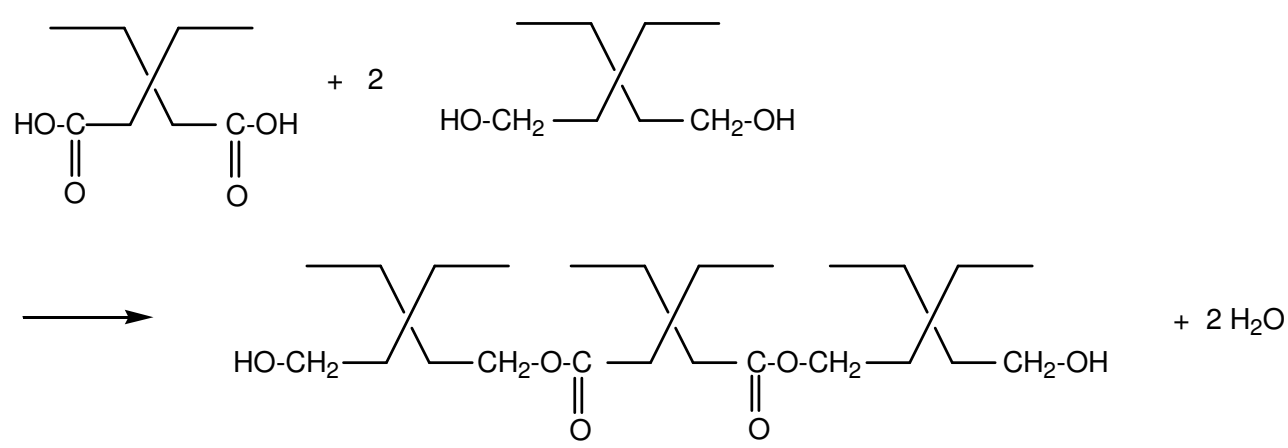

Only 1 cycloaliphatic diamine, 4,4'-diamino-3,3'-dimethyl dicyclohexyl methane (3-DCM, or Laromin C260, BASF), was used as a chain extender. The chain extension stage was carried out in solution, using tetrahydrofuran (THF) (SDS, purity.99.7\%) as received. Dibutyltin dilaurate (DBTDL, Fluka) was used as the catalyst.

\section{Diisocyanate Prepolymer Synthesis}

The NCO-to-OH ratio was always 3.3, in order to take into account the possible side reactions of the isocyanate groups. Diisocyanate prepolymers based on $\mathrm{H}_{12} \mathrm{MDI}$ and reactive oligomers were prepared in bulk at $80^{\circ} \mathrm{C}$ under nitrogen. When the synthesis was catalyzed, $0.04 \mathrm{wt} \%$ DBDTL was added at the beginning of the reaction. For every synthesis, the reaction was followed by the disappearance of the diisocyanate monomer peak in the size exclusion chromatography (SEC) chromatograms. The $\mathrm{H}_{12} \mathrm{MDI}$ conversion was calculated thanks to an internal calibration with the help of an inert probe (naphthalene in this case).

\section{Segmented Polyurethane Urea Synthesis}

The initial NCO-to- $\left(\mathrm{OH}+\mathrm{NH}_{2}\right)$ ratio was again always chosen equal to 1.1. In other words, the overall composition of all reactive mixtures was 1 mol oligomer for 3.3 mol diisocyanate and 2 mol chain extender.

Polyurethane ureas were synthesized by a two-stage polycondensation method. The synthesis procedure can be described as follows:

1. diisocyanate prepolymer synthesis;

2. dissolution of the prepolymer in THF ( $7 \mathrm{wt} \%)$ at room temperature and addition of the catalyst (DBTDL);

3. addition of the chain extender, then reaction at room temperature for $24 \mathrm{~h}$.

For all syntheses, the end of the reaction was assumed to be reached when the isocyanate peak in the Fourier transform infrared (FTIR) spectrum $\left(2270 \mathrm{~cm}^{-1}\right)$ reached a constant value. Spectra were collected on solution-prepared samples with a Nicolet Magna IR 550 spectrometer, using a resolution of $4 \mathrm{~cm}^{-1}$. The polymers were then dried in a vacuum oven for $12 \mathrm{~h}$ at $80^{\circ} \mathrm{C}$ to ensure complete solvent removal. Polyurethane ureas were finally pressed in a mold $\left(130^{\circ} \mathrm{C}, 100\right.$ bars $)$ for $30 \mathrm{~min}$. 
The average molar masses and their distributions were determined by SEC using a Waters chromatograph with a double detection [ultraviolet (UV) at $\lambda=254 \mathrm{~nm}$ and differential refractometer]. The eluent used was THF, and the separation was carried out either on $4 \mu$-styragel columns $\left(10^{5}, 10^{4}\right.$, $10^{3}$, and $500 \AA$ ) or on 2 Nucleogel columns (500 and $100 \AA$ ). The molar mass calibration curves were obtained from polystyrene standards.

Polyurethane ureas were not entirely soluble in THF due to the high crystallinity of the hard segments. For this reason, a solubilization method was used. It consisted in a partial chemical modification of the polymer chains, based on the reaction of urethane and urea groups with trifluoroacetic anhydride (as reported earlier ${ }^{2}$ ).

A differential scanning calorimeter (Mettler TA3000) was used for glass transition temperature measurements $\left(T_{g}\right)$, with a heating rate of $7.5 \mathrm{~K} / \mathrm{min}$. Sample masses were typically $10-20 \mathrm{mg}$. The $T_{g}$ was taken as the onset of the phenomenon.

The dynamic mechanical properties were measured on a Rheometrics RSA II apparatus, at a frequency of $1 \mathrm{~Hz}$. For tensile testing, rectangular samples of 23.2 (length) X 35 (width) $\times 31 \mathrm{~mm}$ (thickness) were used. The heating rate was $3^{\circ} \mathrm{C} / \mathrm{min}$.

Uniaxial stress-strain experiments were carried out with a M30K tensile testing apparatus from JJ Instruments at room temperature, with a crosshead speed of $50 \mathrm{~mm} / \mathrm{min}$. Samples were cut with a NF51034 die and had a gauge length of $20 \mathrm{~mm}$.

\section{RESULTS AND DISCUSSION}

\section{Isocyanate-Terminated Prepolymers}

SEC has often been used to describe the kinetics of the synthesis of diisocyanate prepolymers. ${ }^{7,8}$ Surivet et al. ${ }^{9}$ used SEC measurements to investigate the kinetics of the reaction between $\mathrm{H}_{12} \mathrm{MDI}$ and benzyl alcohol (BZA) in bulk. Mixtures containing $1 \mathrm{~mol} \mathrm{H}_{12} \mathrm{MDI}$ and $1 \mathrm{~mol} \mathrm{BZA}$ (that is $\mathrm{NCO}: \mathrm{OH}=2$ ) were studied according to a simple scheme (Scheme 1).

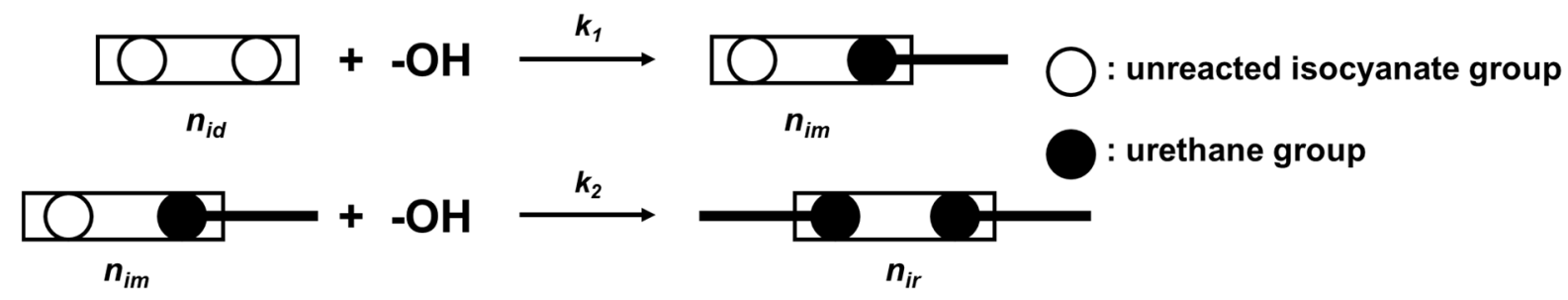

Scheme 1

The authors used the final concentrations of the 3 types of species to determine the relative reactivity ratio of $k_{2}$ to $k_{1}$. At $80^{\circ} \mathrm{C}$, this ratio was found equal to 0.5 (equal reactivity would imply $k_{2}: k_{1}=1$ ). More generally, using a formalism slightly different from the formalism of Peebles, ${ }^{10}$ Nabeth et al. ${ }^{11}$ developed this kinetic scheme in order to describe the reaction between a diisocyanate and hydroxyfunctional compounds by relating the initial OH-to-NCO ratio $\left(r_{H}\right)$ to the reactivity ratio of $\mathrm{k}_{2}$ to $\mathrm{k}_{1}$ (or rather to the parameter $S=k_{2}: 2 k_{1}$ ) and to the relative amount of residual diisocyanate molecules $n_{i d}$. Assuming that there was no side reaction, that all the once-reacted diisocyanate moieties had the 
same reactivity, whatever the molar mass of the molecule, and that all hydroxyl groups were equireactive, they found the following equation at full conversion of the $\mathrm{OH}$ groups:

$$
2\left(1-r_{H}\right)=2 n_{i d}+\frac{1}{1-S} \bullet\left(n_{i d} S-n_{i d}\right)
$$

Equation (1) is equivalent to the equation found by Peebles. ${ }^{10}$

In this work, we attempted to model the first stage of the synthesis with the help of eq. (1). Using an initial NCO-to-OH ratio equal to 3.3 , the value of $k_{2}$ to $k_{1}$ equals 0.5 would correspond to a residual diisocyanate amount equal to $45.15 \%$ of its initial concentration. Equireactivity (no substitution effect; that is, $k_{2}: k_{1}=1$ ) would imply $n_{\text {id }}$ equals $48.58 \%$. More generally, in any case, according to eq. (1), $n_{\text {id }}$ should always fall between $39.39 \%\left(k_{2}: k_{1} \rightarrow 0\right)$ and $69.70 \%\left(k_{2}: k_{1} \rightarrow \infty\right)$.

Table I : Chemical structure and thermal characteristics of the reagents

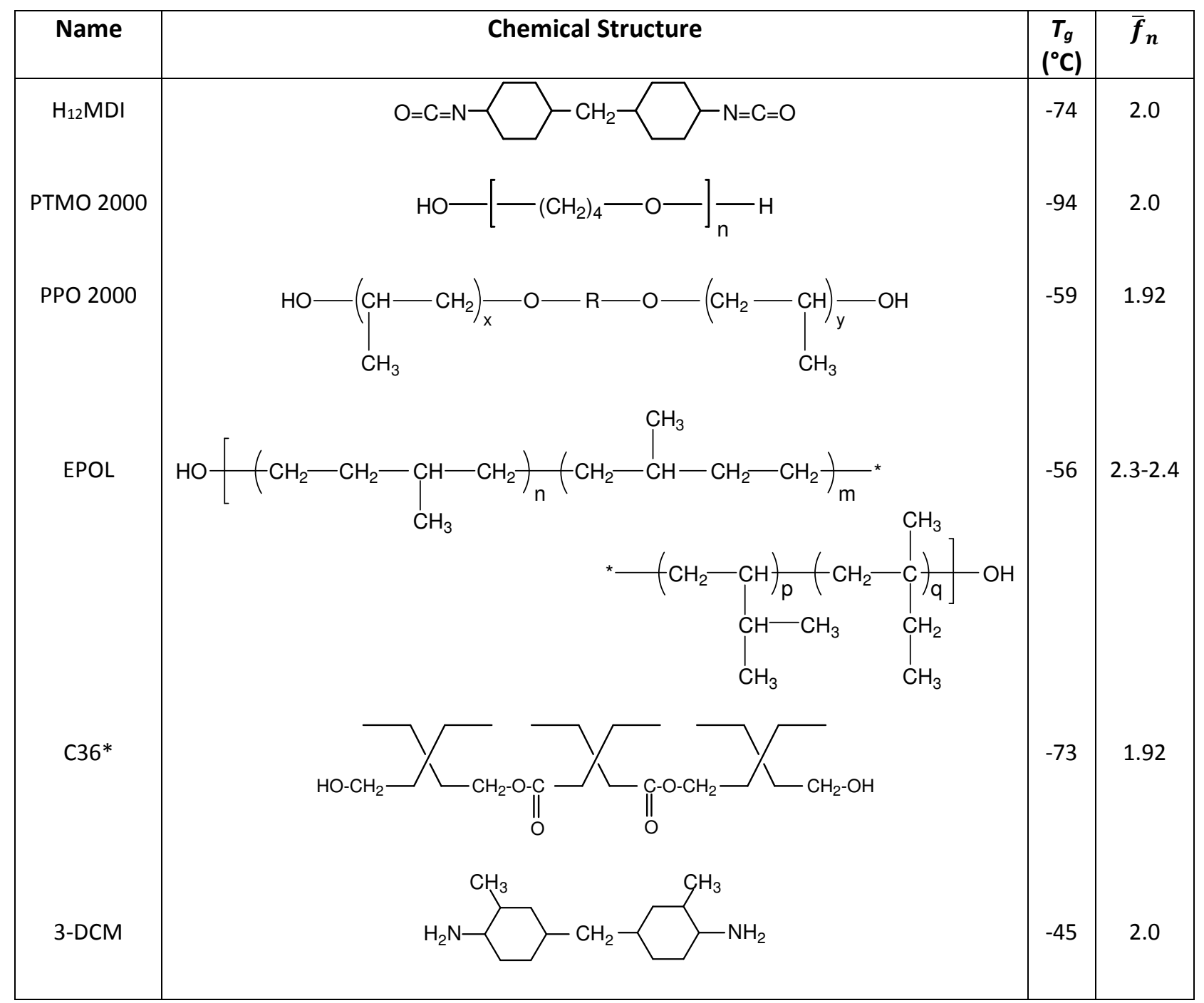

Isocyanate-terminated prepolymers were prepared, and their final mass distribution and residual $\mathrm{H}_{12} \mathrm{MDI}$ content were checked by SEC. Four dihydroxy-telechelic oligomers were used for this purpose; their main characteristics are given in Table I, whereas their SEC chromatograms are depicted in Figure 1. Typical chromatograms obtained for diisocyanate-terminated prepolymers (end of the first stage of the synthesis) are given in Figure 2, whereas all the residual $\mathrm{H}_{12} \mathrm{MDI}$ amounts obtained under 
various conditions are gathered in Table II. It turned out that with every nonpolar prepolymer, and with or without a catalyst, the residual diisocyanate amount fell in between the value obtained by Surivet ${ }^{9}$ (that is, $\mathrm{k}_{2}: \mathrm{k}_{1}=0.5 ; n_{i d}=45.15 \%$ ) and that expected for equireactivity ( $n_{\text {id }}=48.58 \%$ ). The same result was observed for PTMO when DBTDL was added. Given the hypotheses made above, the precision of our SEC measurements and the great variation in $k_{2}: k_{1}$ implied by a small variation in $n_{i d}$, it is thus difficult to estimate $k_{2}: k_{1}$ more precisely, in as much as Surivet used a monofunctional alcohol, which should lead to more precise results.

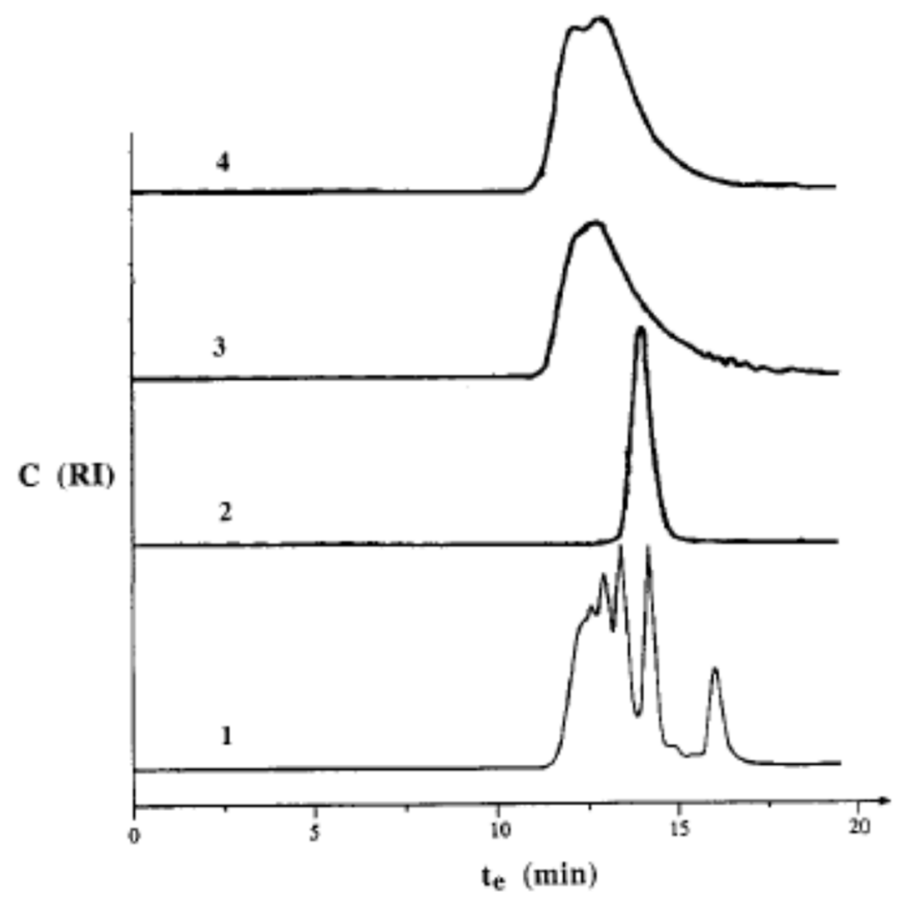

Figure 1 : SEC chromatograms (refractometric detection) of the starting polyols: (1) C36*; (2) PPO2000; (3) PTMO2000; (4) EPOL.

Table II : SEC characterization of isocyanate prepolymers based on $\mathrm{H}_{12} \mathrm{MDI}$

\begin{tabular}{|c|c|c|c|c|}
\hline Starting oligomer and procedure & $\begin{array}{c}\overline{M_{n}} \\
\left(\mathrm{~g} \mathrm{~mol}^{-1}\right)^{\mathrm{a}, \mathrm{b}}\end{array}$ & $\begin{array}{c}\overline{M_{w}} \\
\left(\mathrm{~g} \mathrm{~mol}^{-1}\right)^{\mathrm{a}, \mathrm{b}}\end{array}$ & $I_{p}=\frac{\overline{M_{w}}}{\overline{M_{n}}}$ & $\begin{array}{c}\text { Residual } \mathrm{H}_{12} \mathrm{MDI} \\
\text { (\%) }\end{array}$ \\
\hline PTMO 2000, uncatalyzed & 3600 & 6200 & 17 & 69 \\
\hline PTMO 2000, catalyzed & 5300 & 8600 & 1.6 & 46 \\
\hline C36*, uncatalyzed & 3900 & 6400 & 1.6 & 47 \\
\hline C36*, catalyzed & 4200 & 6600 & 1.6 & 46 \\
\hline EPOL, uncatalyzed & 6000 & 9900 & 1.6 & 48 \\
\hline EPOL, catalyzed & 6800 & 11000 & 1.6 & 47 \\
\hline PPO 2000, uncatalyzed & 2800 & 2900 & 1.0 & 79 \\
\hline PPO 2000, catalyzed & 5200 & 6400 & 1.2 & 33 \\
\hline PPO 2000, $\mathrm{NCO}$ to $\mathrm{OH}=1$, dropwise & 63400 & 102400 & 1.6 & 0 \\
\hline
\end{tabular}

a Polystyrene calibration.

b Oligomer and polymer peak only. 
In contrast, $2 \mathrm{~h}$ were not sufficient for the completion of the first stage with PPO and PTMO when no catalyst was used. The isocyanate-alcohol reaction is actually known to proceed slower in a more polar media, ${ }^{12}$ which could be the case with polyether chains. Finally, the residual amount of $\mathrm{H}_{12} \mathrm{MDI}$ (33\%) was found lower than any possible theoretical value when the modification of PPO was carried out in the presence of DBTDL, in agreement with the presence of some by-products in the SEC chromatogram (see Fig. 2). Anomalous behaviors have already been encountered in the synthesis of PPO-based diisocyanate prepolymers when using meta- $\alpha, \alpha, \alpha, \alpha$-tetramethyl xylylene diisocyanate ( $m$-TMXDI) with a ferric catalyst. ${ }^{8}$

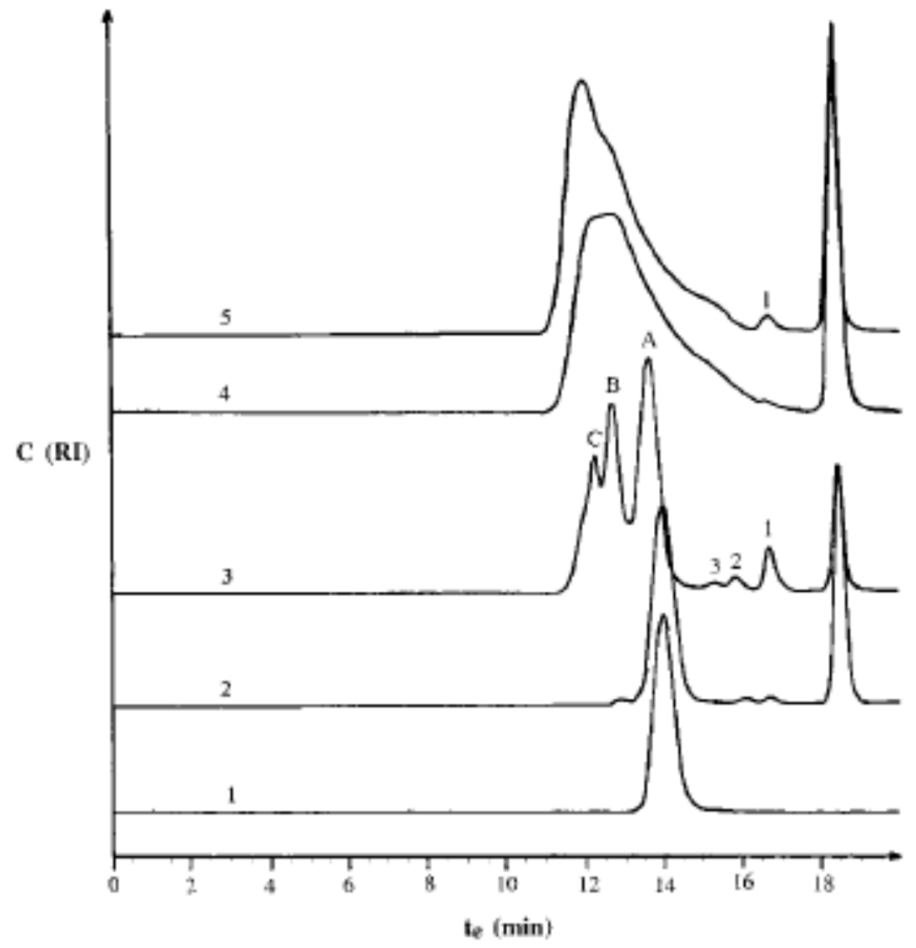

Figure 2 : SEC chromatograms (refractometric detection) of typical diisocyanate-terminated prepolymers: (1) PPO2000; (2) PPO2000- $\mathrm{H}_{12} \mathrm{MDI}$ (1 : 3.3), uncatalyzed (bulk, 80 20 h); (3) PPO2000- $\mathrm{H}_{12} \mathrm{MDI}\left(1: 3.3\right.$ ), catalyzed (bulk, $80^{\circ} \mathrm{C}, 4 \mathrm{~h}$ ); (4) PTMO2000- $\mathrm{H}_{12} \mathrm{MDI}$ (1: 3.3), uncatalyzed (bulk, $80^{\circ} \mathrm{C}, 13 \mathrm{~h}$ ); (5) PTMO2000- $\mathrm{H}_{12} \mathrm{MDI}\left(1: 3.3\right.$ ), catalyzed (bulk, $80^{\circ} \mathrm{C}, 2 \mathrm{~h}$ ).

The catalyzed reaction kinetics at $80^{\circ} \mathrm{C}$ was thus investigated more precisely by SEC. Figure 3 depicts the evolution of the concentrations of various species with time. It appears that the diisocyanate peak decreases at first rapidly; after remaining almost constant for 2 to $3 \mathrm{~h}$, it starts decreasing again. The first decrease in $\mathrm{H}_{12} \mathrm{MDI}$ concentration is associated with the appearance of the 3 expected peaks $\mathrm{A}, \mathrm{B}$, and $\mathrm{C}$ (trimer $\mathrm{H}_{12} \mathrm{MDI}-\mathrm{PPO} 2000-\mathrm{H}_{12} \mathrm{MDI}$; pentamer $\mathrm{H}_{12} \mathrm{MDI}-\mathrm{PPO} 2000-\mathrm{H}_{12} \mathrm{MDI}-\mathrm{PPO} 2000-\mathrm{H}_{12} \mathrm{MDI}$; and heptamer $\mathrm{H}_{12} \mathrm{MDI}-\mathrm{PPO} 2000-\mathrm{H}_{12} \mathrm{MDI}-\mathrm{PPO} 2000-\mathrm{H}_{12} \mathrm{MDI}-\mathrm{PPO} 2000-\mathrm{H}_{12} \mathrm{MDI}$ ) and of higher $i$ mers. But peak 1 is already present and keeps increasing until 2 other unexpected peaks ( 2 and 3 ) appear, whereas the diisocyanate peak starts decreasing again. The associated species must thus result from side reactions of $\mathrm{H}_{12} \mathrm{MDI}$ with itself (formation of dimer or trimer) or with water and can also account for the abnormally low value of $n_{i d}$ found in this case. As shown in Figure 4 , the same peaks were obtained when reacting $\mathrm{H}_{12} \mathrm{MDI}$ directly with water or with 4,4'-diamino-dicyclohexylmethane, PACM (PACM could be produced by the hydrolysis of both isocyanate functions of $\mathrm{H}_{12} \mathrm{MDI}$ ). These side reactions are favored both by the very low reactivity of PPO2000 (secondary alcohols) and by its 
important hydrophilicity. The consequence for industrial application is that the use of an isocyanateterminated prepolymer based on PPO is quite difficult at $80^{\circ} \mathrm{C}$ since its uncatalyzed synthesis is very slow, whereas the use of a catalyst is not necessarily a better solution since it leads to the loss of diisocyanate molecules in some by-products. The time when the residual diisocyanate amount is almost stable and roughly corresponds to the value found for other polyols ( $n_{i d}=46 \%$ ) is quite short (around $20 \mathrm{~min}$ in our case), which means that this catalyzed prepolymer cannot be stored. To avoid losing part of the isocyanate groups in side reactions, the second stage must be run precisely starting from $t=20$ min under these conditions. To look at the effect of incomplete reaction and of the degree of mixing between hard and soft phases, another synthetic procedure was investigated for this particular prepolymer. In this case, $\mathrm{H}_{12} \mathrm{MDI}$ was at first added dropwise to the mixture of PPO2000 and catalyst until stoichiometry $(\mathrm{NCO}-\mathrm{to}-\mathrm{OH}=1.0$ ) was reached. The excess diisocyanate was then added at once. Quite logically, in doing so, the second NCO group of a diisocyanate molecule is forced to react. Thus, as shown in Figure 5, the final prepolymer exhibits high molar masses and homogeneous mass distribution, as opposed to the first synthesized prepolymer.

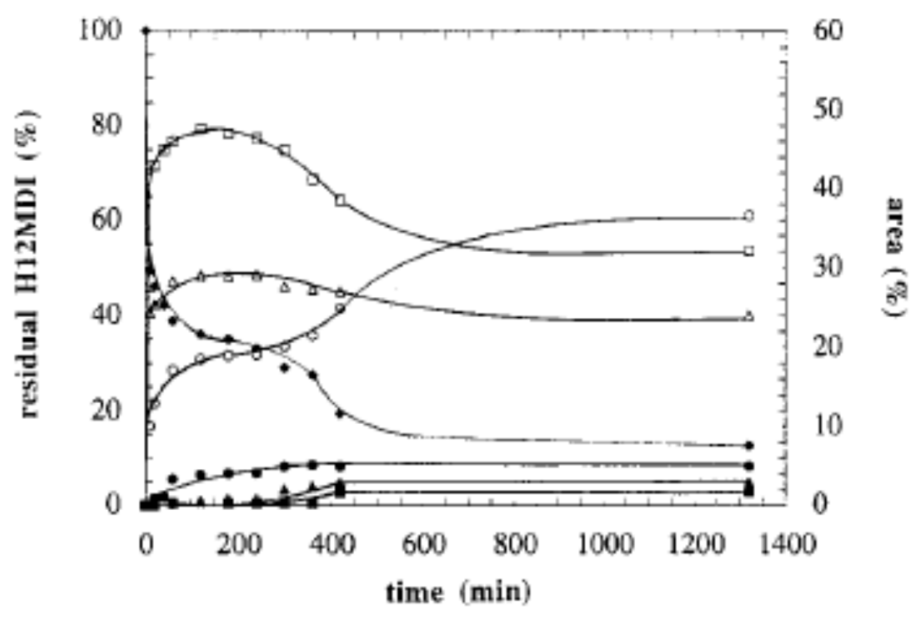

Figure 3 SEC analysis of the kinetics of the PPO2000- $\mathrm{H}_{12} \mathrm{MDI}(1: 3.3)$ reaction $\left(80^{\circ} \mathrm{C}\right.$, bulk) in the presence of DBTDL: $(\diamond)$ residual amount of $\mathrm{H}_{12} \mathrm{MDI}$ and relative areas of $(\mathrm{O})$ peak $(\mathrm{C})$ (heptamer); $(\triangle)$ peak (B) (pentamer); $(\square)$ peak (A) (trimer); (D) peak 3; $(\Delta)$ peak 2; (O) peak 1.

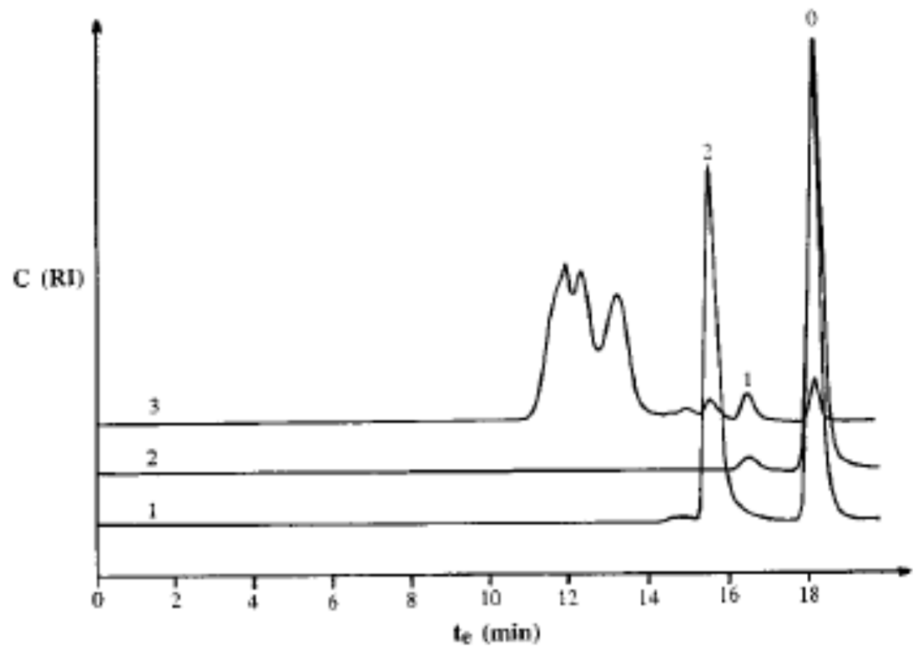

Figure 4 : SEC chromatograms (refractometric detection) of model reactive mixtures: (1) PACM + $\mathrm{H}_{12} \mathrm{MDI}(1: 3.3)$, soluble fraction; (2) $\mathrm{H} 2 \mathrm{O}+\mathrm{H}_{12} \mathrm{MDI}(1: 1)\left(50^{\circ} \mathrm{C}, 24 \mathrm{~h}\right)$; (3) PPO2000 + $\mathrm{H}_{12} \mathrm{MDI}(1: 3.3)$ + DBTDL $\left(80^{\circ} \mathrm{C}, 22 \mathrm{~h}\right)$. 


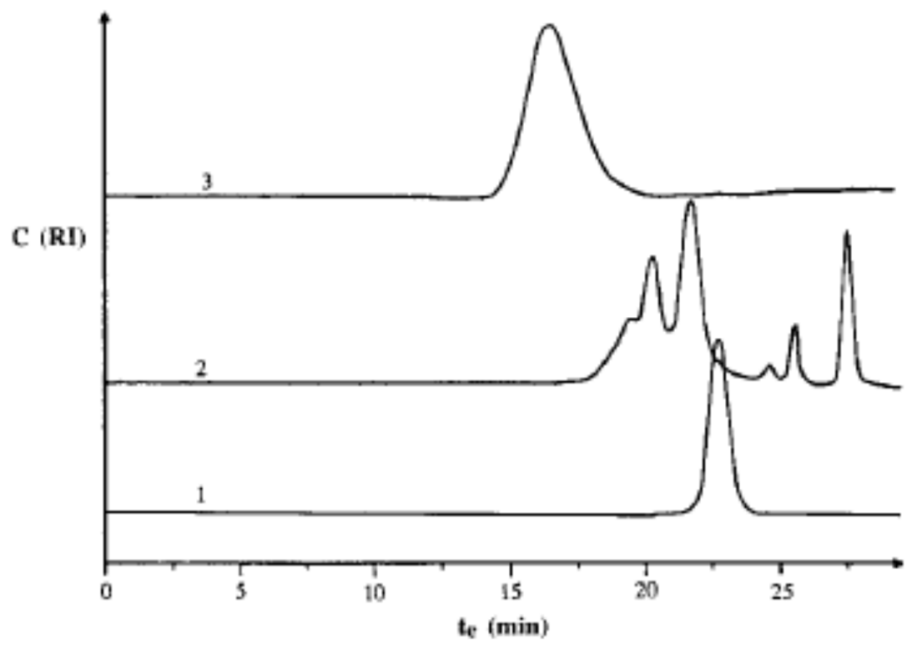

Figure 5 : SEC chromatograms (refractometric detection) of (1) PPO2000; (2) PPO2000 + $\mathrm{H}_{12} \mathrm{MDI}(1$ : 3.3) + DBTDL $\left(80^{\circ} \mathrm{C}, 4 \mathrm{~h}\right.$, standard procedure); (3) PPO2000 + $\mathrm{H}_{12} \mathrm{MDI}(1: 1)\left(80^{\circ} \mathrm{C}, 12 \mathrm{~h}\right.$, dropwise addition).

\section{Synthesis of Segmented Polyurethane Ureas}

Every synthesis of segmented polyurethane urea was catalyzed, since it was shown earlier ${ }^{2}$ that the second stage needed to be catalyzed in order to obtain high molar masses. In doing so, the polymerization rate is allowed to compete with hard segment crystallization, which would otherwise stop the reaction and lead to an off-stoichiometric two-phase system with very low molar masses.

At first, the reacting system was completely soluble in THF. At the end of the reaction, the solution still looked clear but had become very viscous. The use of a filter $(0.45 \mathrm{~mm}$ porosity) revealed that some reaction products were, in fact, not soluble in THF due to the partial crystallization of some hard segments. The molar masses obtained for the various soluble fractions are gathered in Table III.

Table III : SEC characterization (soluble fractions in THF after chemical modification by trifluoroacetic anhydride) and DSC analysis of the segmented polyurethane areas ${ }^{a}$

\begin{tabular}{|c|c|c|c|c|c|c|}
\hline Soft Segment Precursor & $\begin{array}{c}\overline{M_{n}} \\
\left(\mathrm{~g} \mathrm{~mol}^{-1}\right)^{\mathrm{b}}\end{array}$ & $\begin{array}{c}\overline{M_{w}} \\
\left(\mathrm{~g} \mathrm{~mol}^{-1}\right)^{b}\end{array}$ & $I_{p}^{b}$ & $\begin{array}{c}\text { Precursor } \\
T_{g}\left({ }^{\circ} \mathrm{C}\right)\end{array}$ & $T_{g}^{s}\left({ }^{\circ} \mathrm{C}\right)$ & $T_{m}{ }^{h}\left({ }^{\circ} \mathrm{C}\right)$ \\
\hline PTMO 2000 & 62,200 & 120,000 & 1.9 & -94 & -84 & $\approx 350$ \\
\hline C36* & 34,300 & 75,000 & 2.2 & -59 & -52 & $\approx 350$ \\
\hline PPO 2000 (standard procedure) & 36,000 & 83,200 & 2.3 & -74 & -59 & $\approx 350$ \\
\hline PPO 2000 (dropwise procedure) & 46,600 & 110,000 & 2.3 & -74 & -95 & $\approx 350$ \\
\hline EPOL & $--^{--}{ }^{c}$ & $----^{c}$ & $---c^{c}$ & -56 & -56 & $\approx 350$ \\
\hline
\end{tabular}

a Soft segment- $\mathrm{H}_{12} \mathrm{MDI}-3 \mathrm{DCM}=1: 3.3: 2$.

b According to a polystyrene calibration.

c Crosslinked polymer. 
Due to its initial $\mathrm{OH}$ functionality higher than 2.0, the polymer based on EPOL was quite insoluble and could not be characterized. Polyurethane ureas based on PTMO2000 and C36* display rather symmetrical mass distributions; average molar masses are in the range of $\overline{M_{n}}$ equal to $34000 \mathrm{~g} \mathrm{~mol}^{-1}$ and $\overline{M_{w}}$ equal to $75000 \mathrm{~g} \mathrm{~mol}^{-1}$ for the polyurethane urea based on C36* and $\overline{M_{n}}$ equal to $62000 \mathrm{~g} \mathrm{~mol}^{-1}$ and $\overline{M_{w}}$ equal to $120000 \mathrm{~g} \mathrm{~mol}^{-1}$ for that based on PTMO2000. In the literature, lower molar masses were obtained by Gunatillake et al. ${ }^{13}$ when reacting PTM01000 with the less-reactive $m$-TMXDI and diethyltoluenediamine (DETDA) chain extender. Using more reactive aliphatic diamine chain extenders, high molar masses could be obtained, confirming the above stated explanation. The same conclusion can be drawn from the works of Joel et al. ${ }^{14}$ (diisocyanate, 4,4'-diphenylmethane diisocyanate, MDI; chain extender, ethylene diamine, EDA) and Lee and $\mathrm{Ko}^{15}$ (diisocyanate, MDI; aromatic chain extenders) who could obtain very high molar masses by using sufficiently reactive hard segment precursors.

Two segmented copolymers were obtained from PPO2000, as follows: the first by the standard synthetic procedure described in the experimental part and another from the prepolymer obtained by the dropwise addition of $\mathrm{H}_{12} \mathrm{MDI}$ (the second stage being carried out just as above). We could notice at first that a slight increase in molar mass was induced by the addition of the excess $\mathrm{H}_{12} \mathrm{MDI}$, which suggests that the theoretical stoichiometry ( $\mathrm{NCO}: \mathrm{OH}=1$ ) was, in fact, not reached, presumably because of some early side reactions. Segmented polyurethane ureas obtained by both synthesis procedures can be compared in Figures 6 and 7 .

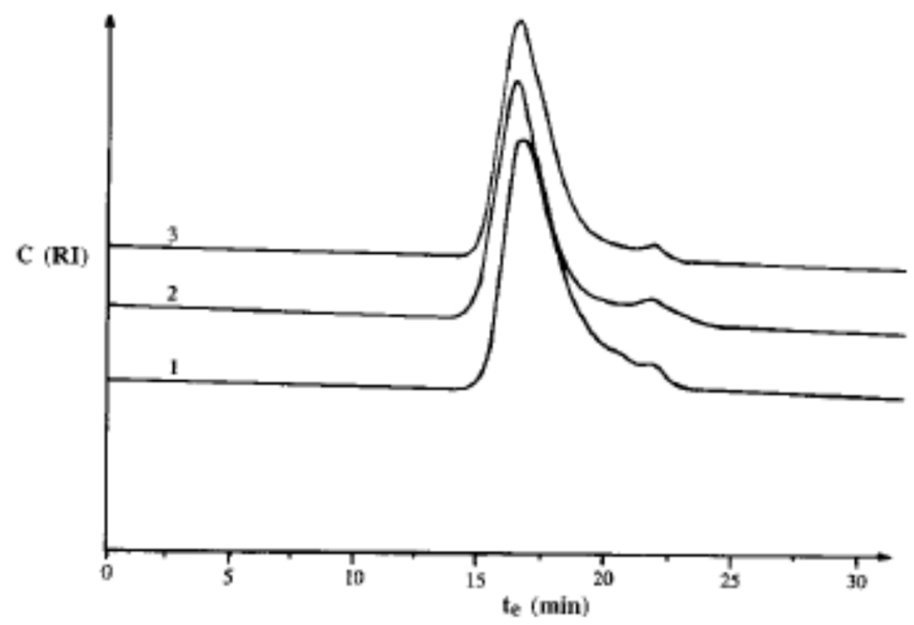

Figure 6 SEC chromatograms (refractometric detection) of the segmented polyurethane urea PPO2000- $\mathrm{H}_{12} \mathrm{MDI}-3 \mathrm{DCM}$ (1 : $3.3: 2$, standard procedure): (1) before solvent removal; (2) after solvent removal; (3) after pressing $\left(130^{\circ} \mathrm{C}, 30 \mathrm{~min}\right)$. 


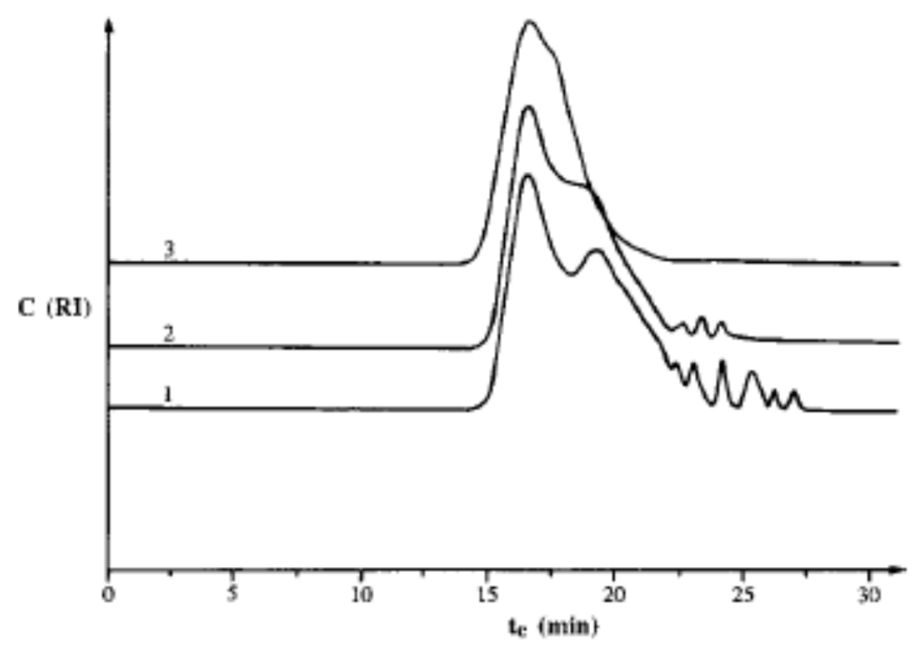

Figure $7 \mathrm{SEC}$ chromatograms (refractometric detection) of the segmented polyurethane urea PPO2000- $\mathrm{H}_{12} \mathrm{MDI}-3 \mathrm{DCM}$ (1 : $3.3: 2$, dropwise procedure): (1) before solvent removal; (2) after solvent removal; (3) after pressing $\left(130^{\circ} \mathrm{C}, 30 \mathrm{~min}\right)$.

For the standard polyurethane urea, Figure 6 shows that the mass distribution remains unimodal at every stage of the reaction, whereas it looks bimodal for the dropwise procedure. In other words, every chain grows between stage 1 and stage 2 of the standard procedure, which means that soft chains are extended by hard segments. In contrast, using the dropwise procedure long soft chains were synthesized during the prepolymer stage so that there are very few isocyanate-terminated chains together with nonreacted diisocyanate molecules. It can be seen that between stage 1 and stage 3 , the mass distribution of the soft chains remains quasi-constant while that of the hard segments broadens. At the end of the synthesis, there are probably 2 populations, such as long soft chains and isolated hard segments, essentially linked by hydrogen bonds. Table III shows that the molar masses are finally higher, which is not necessarily a correct indication in this particular case, as will be shown with the dynamic mechanical properties.

The thermal properties measured by differential scanning calorimetry (DSC) are reported in Table III. All materials are phase-segregated, with a low glass transition temperature of the soft phase. The values are equal or only slightly higher than those of the corresponding polyols, denoting that the chain ends have lost part of their mobility but that this soft phase is nevertheless rather pure. The sample prepared with the dropwise procedure exhibits a lower $T_{g}\left(-65^{\circ}\right)$ than its standard counterpart, which suggests that soft chains have more mobility because they are not chemically linked with the isolated hard segments. DSC curves display a melting endotherm at high temperature $\left(T_{m} \approx 350^{\circ} \mathrm{C}\right)$ for all segmented polyurethane ureas, which results from the melting of the crystalline part of the hard phase.

\section{Effect of the Nature of the Polyol on the Dynamic Mechanical Properties}

At first, we compare polyurethane ureas based on PTMO2000, EPOL, C36*, and PPO2000. Their dynamic mechanical properties are reported in Table IV, whereas the corresponding spectra are displayed in Figures 8 and 9 . All the materials contained around $40 \mathrm{wt} \%$ hard segments and were postcured. In a previous work, ${ }^{2}$ it was actually shown that postcuring at high temperature could benefit 
the thermomechanical properties of closely related segmented polyureas. Longer and higher rubbery plateaux were obtained after postcuring for $90 \mathrm{~min}$ at $200^{\circ} \mathrm{C}$, as a result of both chain extension, creation of intermolecular linkages, and improvement of the level of microphase separation. In this work, the best results were also obtained when polyurethane ureas were postcured at $200^{\circ} \mathrm{C}$, except those derived from PPO2000. The latter degraded at high temperature and were thus postcured only at $160^{\circ} \mathrm{C}$.

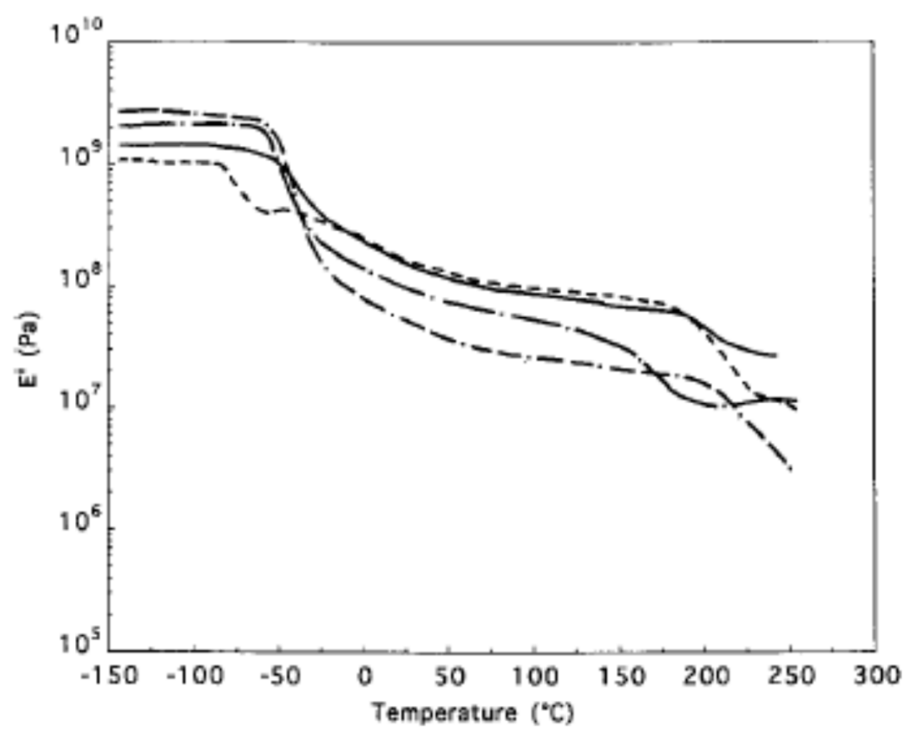

Figure 8 : Storage modulus $E^{\prime}$ of segmented polyurethane ureas based on different polyols: (- - - -) PTMO2000- $\mathrm{H}_{12} \mathrm{MDI}-3 \mathrm{DCM}$ (postcured at $200^{\circ} \mathrm{C}$ ); (--) C36*- $\mathrm{H}_{12} \mathrm{MDI}-3 \mathrm{DCM}$ (postcured at $200^{\circ} \mathrm{C}$ ); $(---)$ EPOL- ${ }_{12} \mathrm{MDI}-3 \mathrm{DCM}$ (postcured at $200^{\circ} \mathrm{C}$ ); (-- -) PPO2000- $\mathrm{H}_{12} \mathrm{MDI}-3 \mathrm{DCM}$ (postcured at $\left.160^{\circ} \mathrm{C}\right)$.

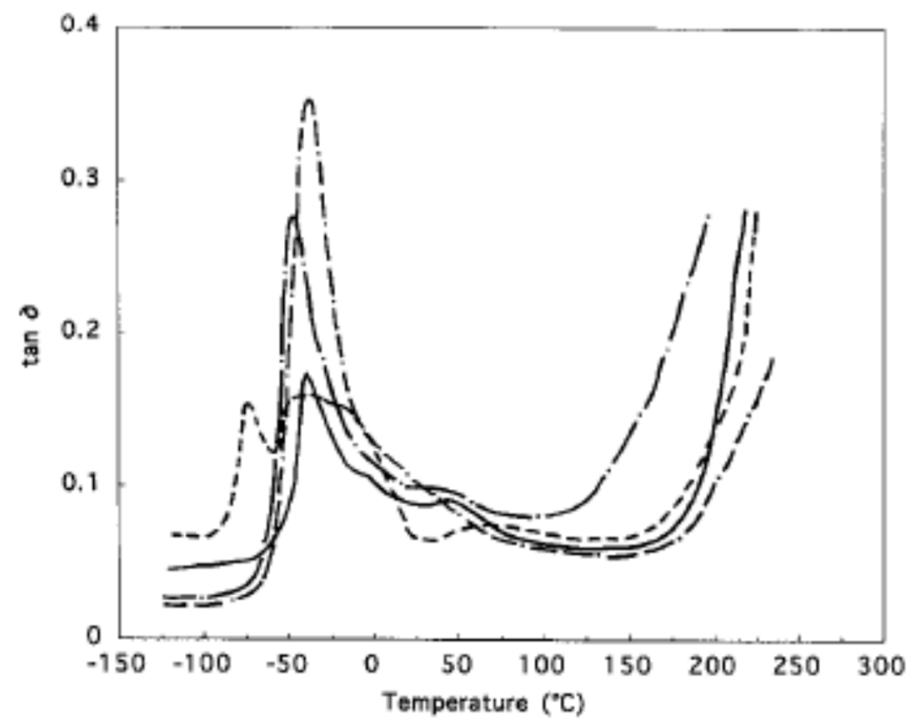

Figure 9 : Loss factor tan $\delta$ of segmented polyurethane ureas based on different polyols: (- - - -) PTMO2000- $\mathrm{H}_{12} \mathrm{MDI}-3 \mathrm{DCM}$ (postcured at $200^{\circ} \mathrm{C}$ ); (--) $\mathrm{C}^{*} 6^{*}-\mathrm{H}_{12} \mathrm{MDI}-3 \mathrm{DCM}$ (postcured at $200^{\circ} \mathrm{C}$ ); (- - -) EPOL- ${ }_{12} \mathrm{MDI}-3 \mathrm{DCM}$ (postcured at $200^{\circ} \mathrm{C}$ ); (-- -) PPO2000- $\mathrm{H}_{12} \mathrm{MDI}-3 \mathrm{DCM}$ (postcured at $\left.160^{\circ} \mathrm{C}\right)$. 
Table IV : Dynamic mechanical properties of segmented polyurethane ureas based on various polyol soft segments ${ }^{\mathrm{a}}$

\begin{tabular}{|c|c|c|c|c|c|c|c|c|}
\hline Soft Segment & HS wt \% & $\begin{array}{l}T_{g}^{s}\left({ }^{\circ} \mathrm{C}\right) \\
\text { (DSC) }\end{array}$ & $\begin{array}{c}T_{\alpha}^{s}\left({ }^{\circ} \mathrm{C}\right)^{\mathrm{b}} \\
(\mathrm{DMS})\end{array}$ & $\begin{array}{c}\text { Height of } \\
\text { Tan } \delta \text { Peak }\end{array}$ & $\begin{array}{l}\text { Height of } \\
\text { Tan } \delta \text { Peak } \\
(100 \% \text { SS) }\end{array}$ & $\begin{array}{c}E_{c}^{\prime}\left(20^{\circ} \mathrm{C}\right) \\
(\mathrm{MPa})\end{array}$ & $\frac{E^{\prime}\left(20^{\circ} C\right)}{E^{\prime}\left(80^{\circ} C\right)}$ & $\begin{array}{c}T_{\alpha}^{h}\left({ }^{\circ} \mathrm{C}\right)^{\mathrm{b}} \\
(\mathrm{DMS})\end{array}$ \\
\hline PTMO 2000 & 40 & -84 & -86 & 0.15 & $0.25^{c}$ & 153 & 1.6 & $\approx 180$ \\
\hline C36* & 38 & -52 & -59 & 0.17 & 0.27 & 154 & 1.8 & $\approx 180$ \\
\hline EPOL & 38 & -53 & -57 & 0.35 & 0.56 & 53 & 2.0 & $\approx 180$ \\
\hline PPO 2000 (standard procedure) & 38 & -59 & -60 & 0.28 & 0.45 & 95 & 1.7 & $\approx 140$ \\
\hline PPO 2000 (dropwise procedure) & $38(30)^{d}$ & -58 & -59 & 1.04 & $1.67(1.49)^{d}$ & 8 & 3.5 & $\approx 120$ \\
\hline D-2000 (diamine) & 39 & -61 & -63 & 0.24 & 1.00 & 155 & 1.3 & $\approx 180$ \\
\hline
\end{tabular}

a Precursor- $\mathrm{H}_{12} \mathrm{MDI}-3 \mathrm{DCM}=1: 3.3: 2$.

$\mathrm{b} T_{\alpha}$ is the temperature associated with the onset of the decrease in $E^{\prime}$.

c Only representative of the amorphous part of the soft phase.

$\mathrm{d} 38 \%$ results from the overall composition (PPO- $\mathrm{H}_{12} \mathrm{MDI}-3 \mathrm{DCM}=1: 3.3: 2$ ); $30 \%$ would be obtained by considering that 1 out of 3.3 diisocyanates has been incorporated into the soft segment. 
Values of $T_{\alpha}^{s}$ corresponding to the relaxation associated with the glass transition of the soft phase are in good agreement with values of $T_{g}^{s}$ obtained by DSC (for the sample based on PTMO2000, a second relaxation around $-40^{\circ} \mathrm{C}$ can be attributed to the crystallization of PTMO blocks in the soft phase). The height of $\tan \delta$ peak obtained for the polyurethane urea based on EPOL is the highest. This means that soft chains based on EPOL are the most flexible, compared to those derived from PTMO2000, C36*, or PPO2000.

The second decrease in $E^{\prime}$, which occurs at high temperature, probably corresponds to the glass transition of the hard phase. For materials based on PTMO2000, C36*, and EPOL, the rubbery plateau is rather long and drops only starting from $180^{\circ} \mathrm{C}$. Such materials can thus find applications at high enough temperatures, in contrast to that based on PPO2000 which, due partly to its lower postcuring temperature, displays less interesting properties.

The properties of polyurethane ureas based on polyether polyols (PTMO or PPO) can be compared with existing literature. Rosthauser et al. ${ }^{16}$ studied polyurethane ureas very similar to ours (that is, based on PPO2000 or PTMO2000, $\mathrm{H}_{12} \mathrm{MDI}$, and DETDA; stoichiometry, $1: 3.5: 2.33$ ) in order to compare them with their counterpart derived from $100 \%$ trans, trans- $\mathrm{H}_{12} \mathrm{MDI}$.

For the classical materials based on the raw Desmodur W, they found the same values as ours for $T_{\alpha}^{s}$ [that is, $-51^{\circ} \mathrm{C}$ (PPO) and $-74^{\circ} \mathrm{C}$ (PTMO) for the maximum of $\tan \delta$ peak], whereas $T_{\alpha}^{h}$ was somewhat lower in their case, presumably because their materials were only cured up to $110^{\circ} \mathrm{C}$.

Takahara et al. ${ }^{17}$ prepared materials based on PTMO or PPO, MDI, and EDA by a solution procedure. Their polyurethane ureas showed slightly higher temperatures for the $\alpha^{\delta}$ relaxation $\left(T_{\alpha}^{s}=-54^{\circ} \mathrm{C}\right.$ for PPO2000-MDI-EDA and $-73^{\circ} \mathrm{C}$ for PTMO 1900-MDI-EDA). This discrepancy is not really significant since the authors used a frequency of $11 \mathrm{~Hz}$ for their measurements instead of $1 \mathrm{~Hz}$ in this work. The degree of phase segregation must thus be comparable in both cases. At a high temperature, they also obtained for the end of the rubbery plateaux values similar to ours $\left(T_{\alpha}{ }^{h} \approx 180^{\circ} \mathrm{C}\right)$. But the rubbery moduli obtained in our case are nonetheless much higher, although the curves look slightly steeper; this might illustrate the effects of a low-temperature curing (maximum curing temperature $=100^{\circ} \mathrm{C}$ in Takahara's work).

Finally, using stress-relaxation measurements on polyurethane ureas based on PPO1000 or PTM01000, $\mathrm{H}_{12} \mathrm{MDI}$, and propylene diamine (stoichiometry, $1: 2: 1$ ), Monteiro and Fonseca ${ }^{18}$ demonstrated that phase segregation was more important for samples based on PTMO. In contrast, as seen in Table IV, no clear conclusion can be drawn from our dynamic mechanical measurements; the peak value of $\tan \delta$, even normalized to $100 \%$ soft segment, is lower in the case of PTMO but does not take into account the crystalline part of the soft phase and it is thus difficult to conclude.

\section{Role of Isolated Hard Segments}

The effect of incomplete reaction and poor phase segregation can be illustrated by comparing the dynamic mechanical properties of the 2 polyurethane ureas based on PPO2000. The polymers have very different aspects; the material obtained from the standard procedure of prepolymer synthesis is transparent, whereas that obtained by a dropwise procedure is opaque. However, both segmented polyurethane ureas have the same hard segment content, but their dynamic mechanical properties are nevertheless quite different (Fig. 10). The maximum values of $T_{\alpha}^{s}$ and $T_{\alpha}^{h}$ are the same, but the rubbery moduli are not identical. Table IV shows that the storage modulus, $E^{\prime}$, is around $100 \mathrm{MPa}$ 
$\left(20^{\circ} \mathrm{C}\right)$ for the standard polymer, whereas $E^{\prime}$ is approximately equal to $10 \mathrm{MPa}\left(20^{\circ} \mathrm{C}\right)$ for the polymer prepared by the dropwise procedure. The latter displays a much steeper rubbery plateau. The $\alpha^{\delta}$ relaxation is also very intense in this case, which means that the soft segments are free to move.

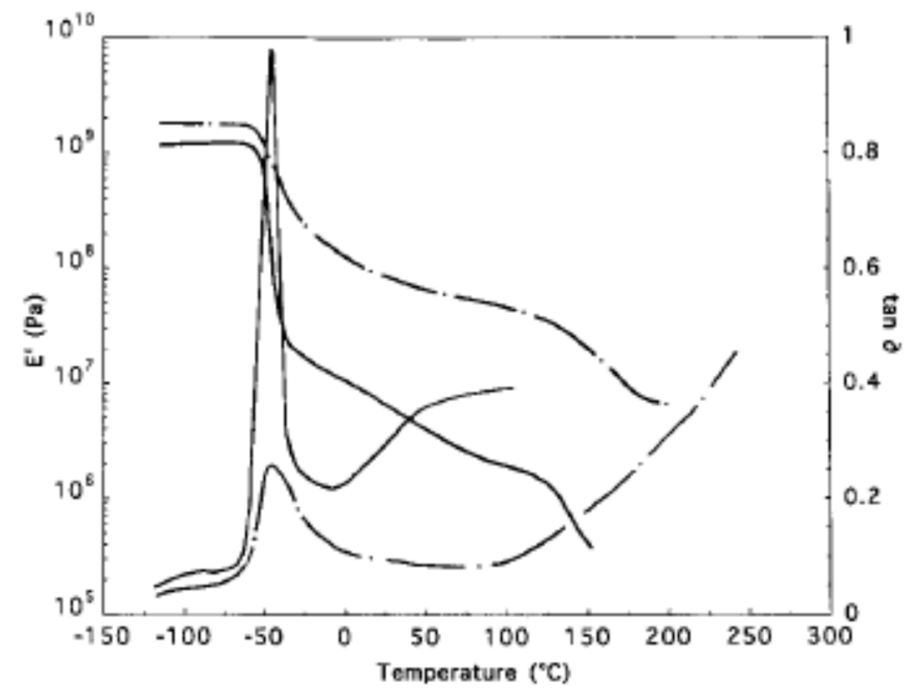

Figure 10 : Storage modulus $\left(E^{\prime}\right)$ and loss factor $(\tan \delta)$ of the segmented polyurethane ureas based on PPO2000, $\mathrm{H}_{12} \mathrm{MDI}$, and 3DCM (1: $\left.3.3: 2\right)$ : (-- -) standard and (--) dropwise prepolymer synthesis.

In fact, this material is merely a blend of 2 polymers (soft and hard segments) with poor miscibility, linked only by hydrogen bonds. All urea hard segments are isolated and only play the role of fillers, which result in a very low rubbery plateau. In contrast, in the standard material hard segments are not isolated but chemically linked to the soft phase and play the role of real physical crosslinks, which lead to good thermomechanical properties. These results are confirmed by the static mechanical properties. Table $\mathrm{V}$ shows that when the polyurethane urea was synthesized by the dropwise procedure, the ultimate stress, $\sigma_{u}$, and Young's modulus, $E$, decrease dramatically while the ultimate strain, $\varepsilon_{u}$, increases compared to the standard polymer. However, none of the materials display any residual strain, presumably because of their overall high molar masses. Both materials represent 2 extreme cases; most of the time, the situation encountered is intermediary, but it is obvious that low amounts of isolated hard segments will rapidly result in a catastrophic decrease in the mechanical properties.

Table V : Static mechanical properties of segmented polyurethane ureas based on PPO $2000, \mathrm{H}_{12} \mathrm{MDI}$, and 3DCM $(1: 3.3: 2)$ and their polyurea counterpart at room temperature

\begin{tabular}{|l|c|c|c|c|}
\hline \multicolumn{1}{|c|}{$\begin{array}{c}\text { Soft Segment and Prepolymer } \\
\text { Synthesis Procedure }\end{array}$} & HS Wt \% & $\sigma_{u}(\mathbf{M P a})$ & $\mathcal{E}_{u}(\%)$ & $E_{\text {Young }}(\mathbf{M P a})$ \\
\hline PPO 2000, standard & 38 & $20 \pm 1$ & $390 \pm 30$ & $10 \pm 5$ \\
PPO 2000, dropwise & 38 & $2 \pm 0.5$ & $420 \pm 30$ & $0.6 \pm 0.5$ \\
D-2000 (diamine) & 39 & $21 \pm 1$ & $320 \pm 30$ & $86 \pm 10$ \\
\hline
\end{tabular}




\section{Comparison Between Polyurethane Ureas and Polyureas}

Finally, a comparison can be drawn between polyurethane ureas and polyureas. In our previous work, ${ }^{2}$ we had prepared a polyurea based on $\mathrm{H}_{12} \mathrm{MDI}, 3 \mathrm{DCM}$, and Jeffamine D-2000, a diamine-terminated polyoxypropylene soft segment with $\overline{M_{n}}<2000$. The diisocyanate prepolymers PPO2000- ${ }_{12} \mathrm{MDI}$ ( 1 : 3.3 , standard procedure) and $\mathrm{D}-2000-\mathrm{H}_{12} \mathrm{MDI}(1: 3.3)$ displayed the same molar mass distribution and both materials were obtained using the same precuring temperature; the polyurea was only postcured at higher temperature $\left(200^{\circ} \mathrm{C}\right)$ than the polyurethane urea $\left(160^{\circ} \mathrm{C}\right)$. They also had comparable molar masses. (Polyurethane urea: $\overline{M_{n}}<36000 ; \overline{M_{w}}<83000$, Polyurea: $\overline{M_{n}}<25000 ; \overline{M_{w}}<52000$.) Figure 11 and Tables IV and $\mathrm{V}$ show better dynamic and static mechanical properties for the polyurea, with a higher and more constant rubbery plateau; the final decrease in $E^{\prime}$ is also observed at a higher temperature in this case. Such an improvement was already observed when comparing closely related polyurethanes and polyurethane ureas, ${ }^{16,19}$ that is, when replacing all urethane groups by urea groups inside the rigid domains; but here, the only difference (apart from the higher postcuring temperature for the polyurea) can be found in the better cohesion of the links between soft and rigid phases induced by the three-dimensional hydrogen bonds between urea groups. ${ }^{20}$ According to the values of $T_{\alpha}^{s}$ and $T_{g}^{s}$ (Table IV), the phase segregation degree might also be slightly higher for the polyurea.

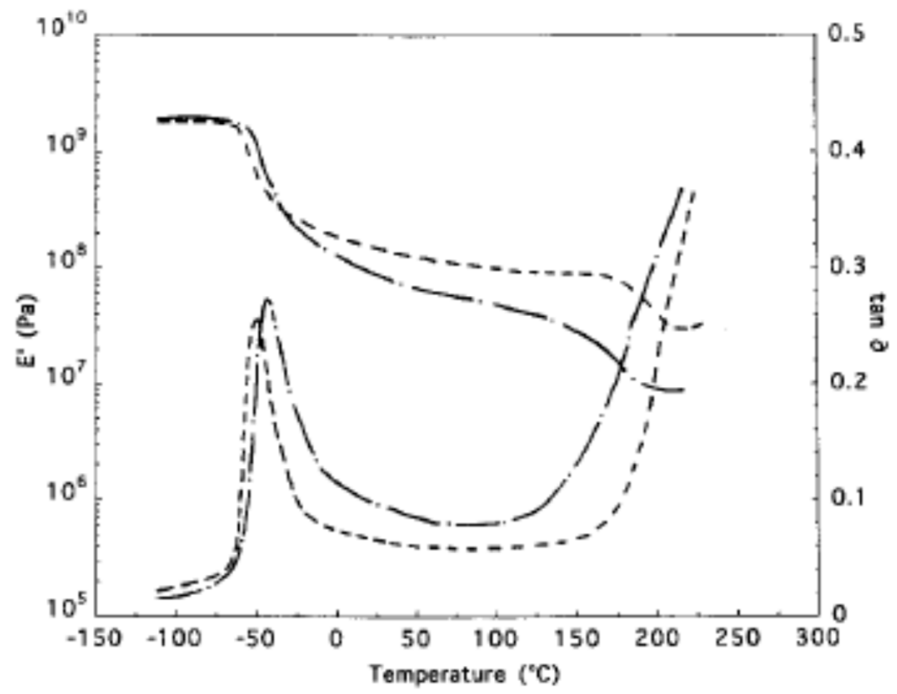

Figure 11 : Comparison between the PPO2000- $\mathrm{H}_{12} \mathrm{MDI}-3 \mathrm{DCM}$ polyurethane urea and its pure polyurea counterpart, D2000- $\mathrm{H}_{12} \mathrm{MDI}-3 \mathrm{DCM}$ : (--) PPO2000- $\mathrm{H}_{12} \mathrm{MDI}-3 \mathrm{DCM}$ (postcured at $160^{\circ} \mathrm{C}$ ); (-----) D2000- $\mathrm{H}_{12} \mathrm{MDI}-3 \mathrm{DCM}$ (postcured at $200^{\circ} \mathrm{C}$ ).

\section{CONCLUSION}

New segmented polyurethane ureas with rigid domains based on commercial 4,4'dicyclohexylmethane diisocyanate (mixture of isomers) and 4,4'-diamino-3,3'dimethyldicyclohexylmethane were obtained using various polar and nonpolar polyols as soft segment precursors. The reactivity of the nonpolar and catalyzed systems was found to be rather uniform, but slower reactions with the occurrence of side products were observed for the noncatalyzed synthesis of polar prepolymers. 
The most critical situation was encountered with polyoxypropylene-based prepolymers, as follows: their synthesis requires the use of a catalyst to be carried out in reasonable times, which implies very short processing windows and does not allow their storage.

All the materials are highly phase-segregated. Whenever their postcuring up to high enough temperature (typically $200^{\circ} \mathrm{C}$ ) is possible, they all display good thermomechanical behaviors. They can thus be used as high-performance elastomers up to approximately $180^{\circ} \mathrm{C}$; that is, they are much better than all common segmented polyurethanes but also compare well with pure polyureas, ${ }^{2}$ which are more difficult to process and for which the number of available soft segments is limited.

In any case, both a high postcuring temperature and the existence of sufficiently numerous chemical links between hard and soft domains were shown to be the most critical parameters for the good thermomechanical characteristics of these materials.

The authors thank the Société SAMI (Malesherbes, France) for the financial support of this work and for many fruitful discussions.

\section{REFERENCES}

1. K. C. Frisch and D. Klempner in ComprehensivePolymer Science, Vol 5, G. C. Eastmond, A. Ledwith,

S. Russo, and P. Sigwalt, Eds, PergamonPress, Oxford, 1989, p. 413.

2. N. Samson, F. Méchin, and J. P. Pascault, J. Appl. Polym. Sci., 65, 2265 (1997).

3. S. D. Seneker and N. Barksby, in Proceedings of the UTECH International Polyurethane Industry Conference, paper 46, The Hague, the Netherlands, 1996.

4. M. F. Llauro, personal communication (1997).

5. F. R. Flandrin, J. M. Widmaier, and J. J. Flat, Polym. Degrad. Stab., 57, 59 (1997).

6. S. Cuney, J. F. Gérard, M. Dumon, J. P. Pascault, G. Vigier, and K. Dusek, J. Appl. Polym. Sci., 65, 2373 (1997).

7. C. M. Thompson, S. G. Taylor, and W. W. McGee, J. Polym. Sci., Part A: Polym. Chem., 28, 333 (1990).

8. C. M. Thompson, S. G. Taylor, and W. W. McGee, J. Polym. Sci., Part A: Polym. Chem., 32, 113 (1994).

9. F. Surivet, T. M. Lam, and J. P. Pascault, J. Polym. Sci., Part A: Polym. Chem., 29, 1977 (1991).

10. L. H. Peebles, Macromolecules, 7, 873 (1974).

11. B. Nabeth, J. P. Pascault, and K. Dusek, J. Polym. Sci., Part B: Polym. Phys., 34, 1031 (1996).

12. S. Ephraim, A. E. Woodward, and R. B. Mesrobian, J. Am. Chem. Soc., 80, 1326 (1958).

13. P. A. Gunatillake, G. F. Meijs, E. Rizzardo, S. J. McCarthy, R. C. Chatelier, A. Brandwood, and K. Schindhelm, J. Appl. Polym. Sci., 47, 199 (1993).

14. D. Joel, W. Hettrich, and R. Becker, Polymer, 34, 2623 (1993).

15. H. K. Lee and S. W. Ko, J. Appl. Polym. Sci., 50, 1269 (1993).

16. J. W. Rosthauser, K. W. Haider, C. Steinlein, and C. D. Eisenbach, J. Appl. Polym. Sci., 64, 957 (1997).

17. A. Takahara, J. Tashita, T. Kajiyama, and M. Takayanagi, Polymer, 26, 987 (1985). 
18. E. E. C. Monteiro and J. L. C. Fonseca, J. Appl. Polym. Sci., 65, 2227 (1997).

19. C. S. P. Sung, T. W. Smith, and N. H. Sung, Macromolecules, 13, 117 (1980).

20. R. Bonart, L. Morbitzer, and E. H. Müller, J. Macromol. Sci. Phys., B9, 447 (1974). 